in the use of terminology and up to date. E. Miller, E.K. Perry and R.H. Perry provide excellent reviews of the psychological, neurochemical and neuropathological aspects of the dementia syndrome.

The chapter on 'Neurological signs in dementia' contains a useful review of the method of neurological examination and the section on the special investigations, computerized tomography and nuclear magnetic resonance imaging is particularly helpful. The reader could be confused by the use of unexplained terminology such as 'primary cerebral atrophy', 'simple senile dementia' and 'primary dementia'.

Continuing management receives scant attention (three pages) whilst seven pages are devoted to a review of drugs used in the treatment of dementia, the efficacy of which has not yet been established.

This book is an introduction to the subject, albeit a somewhat incomplete one. Those looking for information on the impact of dementia on health and social services and on carers, and for the more effective responses that are widely being achieved, will unfortunately not find much of value here - yet surely this is an essential part of 'the clinical approach'.

\section{E.J. Byrne} Department of Health Care of the Elderly, University Hospital, Queen's Medical Centre, Nottingham NG7 $2 U \mathrm{H}$.

Diagnostic Bronchoscopy: a Teaching Manual. Fifth edition, Peter Stradling with the assistance of John R. Stradling. Pp. vi +182 , illustrated. Churchill Livingstone, Edinburgh, London, Melbourne, New York, 1986. £40.00.

The fifth edition of this standard work on bronchoscopy provides a readable and comprehensive review of this important technique. The emphasis is on the indications for, technique of, and observations during bronchoscopy. Both the rigid and fibreoptic methods are fully covered. The indications for bronchoscopy are somewhat overstated and suffer from a lack of consideration of the place of other biopsy procedures, but the section on the practical handling of the bronchoscope is clear and concise. Most of the modern bronchoscopic biopsy and lavage techniques are included, but no mention is made of performing bronchography through the fibreoptic bronchoscope. The normal bronchoscopic findings are fully discussed and well illustrated, together with a useful section on normal anatomical variants. A wide range of abnormal appearances are also shown and in general the standard of photography is high.

The main value of this book is as an aid to practical experience of bronchoscopy. It should be studied by all bronchoscopists during their training, although the price of $£ 40.00$ may limit its readership.

J.M. Shneerson Newmarket General Hospital, Newmarket, Suffolk CB8 $7 J G$.
The ECG Made Easy. Third edition, John R. Hampton. Pp. iii +95 , illustrated. Churchill Livingstone, Edinburgh, London, Melbourne, New York, 1986. £2.75.

Professor Hampton's slim volume on the ECG is now in its third edition. Its laudable aim is to provide GPs, medical students, nurses in CCUs and paramedical staff with a clear concise guide to the ECG. It must be said that the reproduction of the ECGs is good and in general the points made are clearly illustrated.

However, there are a number of errors and inconsistencies in the text. For example, on page 5 and again on page 26 , it is stated that 'the QRS duration is normally $0.12 \mathrm{~s}$ '. This is incorrect, the upper limit of normal is $0.1 \mathrm{~s}$. The description of $P$ waves in nodal extrasystoles and junctional beats, I found confusing. The wording of the example (pages $47 \&$ 52) would be confusing, compared to the text (page 54), for a novice. There is inconsistency on page 57 where it is stated that in atrial tachycardia the atria contract faster than 160 per minute'. Two lines on an example at a rate of 150 per minute is given.

Professor Hampton understates the difficulties in interpretation of tachycardia where the ventricular complex is wide. This distinction between ventricular tachycardia and supraventricular tachycardia with aberrent conduction may be difficult even for the experienced observer. Contrary to the statement on page 62, $P$ waves may be seen during ventricular tachycardia due to independent (dissociated) atrial activity and this feature may help to clarify the diagnosis.

Table 1 shows the most basic methods for treating arrhythmias. I would quarrel with two points. First, although it may well be important to stop digoxin if a patient on this. drug develops arrhythmias, often the first and most usef thing to do is to check the plasma potassium level. These patients are often on diuretics and hypokalaemia may be causing the problem. Second, I am worried by the omission of any mention of DC shock in the immediate treatment of ventricular fibrillation. Two other points, perhaps idiosyncratic: I feel it would be better to write about times in ms rather than decimal portions of a second, i.e. $200 \mathrm{~ms}$ rather than 0.2 seconds. Second, it might help understanding of the relative amplitudes of the ECG deflections due to the relative masses of the right and left ventricle if this was reflected in the illustrations.

Correction of these errors and inconsistencies would not make the text any longer or more complex. Although it is all too easy for minor errors to creep into a text, I would have expected that such matters would have been corrected by the time the third edition had appeared. On the plus side, as well as the good illustrations, there is an adequate index. However, on balance, until these small but important points are attended to, this would not be the first book that I would recommend to the novice in ECGs.

R.A. Greenbaum Harefield Hospital, Harefield, Uxbridge, Middlesex $U B 96 \mathrm{JH}$. 